\title{
A experiência de uma escola rural no contexto do projeto de desenvolvimento local de Massaroca, semi-árido baiano
}

Edmerson dos Santos Reis

Edonilce da Rocha Barros

\section{Resumo}

Apresenta a experiência de uma escola rural idealizada, construída e operacionalizada na dinâmica de um projeto de desenvolvimento local iniciado em 1986, a da Escola Rural de Massaroca (Erum), localizada na Fazenda Lagoinha, no Distrito de Massaroca, município de Juazeiro, situado no coração do semi-árido baiano. A escola foi construída depois de dez anos de existência do "Projeto", a partir de uma demanda do Comitê das Associações Agropecuárias de Massaroca (Caam). A abordagem metodológica baseia-se na utilização dos estudos qualitativos, que permitem respeitar a dimensão temporal de avaliar a causalidade local para formular explicações. O conteúdo revela um dos múltiplos olhares sobre a experiência, sistematizada por educadores que vivenciaram o processo de execução do projeto. Na primeira década de execução deste, as preocupações eram mais voltadas para o campo da produção agropecuária e da organização dos produtores, com o objetivo de assegurar e prosseguir o esforço de geração, adaptação e difusão das inovações tecnológicas. Com a evolução dessas questões, percebeu-se que a educação era o elemento preponderante para o entendimento e a assimilação do novo modo de pensar, agir e viver no local. Surgiu daí a necessidade de introduzir os temas culturais e educativos, firmando-se como prioridades para um desenvolvimento local sustentável vinculado às competências humanas e aos recursos naturais das comunidades, contexto no qual surgiu a Erum.

Palavras-chave: desenvolvimento local; escola rural; comunidade.

\section{Abstract}

The experience of a rural school in the context of the local development project of Massaroca, semi arid region of Bahia State

The article aims at presenting the experience of an idealized rural school, built and operationalised in the context of a local development project that started in 1986. It concerns the Rural School of Massaroca (Erum), located in the Lagoinha Farm, district of Massaroca, Juazeiro, situated in the middle of the semi arid of Bahia state. The school was built after 10 years of existence of the "Project", from a demand of the Farming Associations Committee of Massaroca (Caam). The methodological approach was based on the use of qualitative studies that allow one to respect time dimension; to evaluate the local causalities to formulate explanations. The content of the article discloses one of the multiple approaches to the experience, systematized by educators who have lived the execution process of the project. In the first decade of the execution of the development 
project, the concerns were more driven to farming production and to the organization of the producers, with the objective of ensuring and continuing the effort of generation, adaptation and diffusion of the technological innovations. With the evolution of these questions, one perceived that the education was a key element for the understanding and assimilation of the new way of thinking, acting and living in the region. Therefore, there was the necessity of introducing cultural and educational subjects, prioritizing a sustainable local development linked with human abilities and with the natural resources of the communities, context in which Erum was created.

Keywords: local development; rural school and community.

\section{Introdução}

Em 1986, o conceito de desenvolvimento local ainda não era tão utilizado. Mas foi exatamente nessa década que a Empresa Brasileira de Pesquisa Agropecuária (Embrapa), através de seu Centro de Pesquisa Agropecuária do Trópico Semi-Árido (Cpatsa), localizado em Petrolina-PE, juntamente com o Centre de Coopération Internationale en Recherche Agronomique pour le Développement (Cirad) e a Empresa de Extensão Rural do Estado da Bahia, hoje Empresa Baiana de Desenvolvimento Agrícola (EBDA), selecionaram uma área piloto para implementar uma nova metodologia de ação, com a finalidade de experimentar e validar métodos e instrumentos de ação em apoio ao desenvolvimento local, junto aos agricultores familiares. A experiência foi realizada no Distrito de Massaroca, ${ }^{1}$ no município de Juazeiro, na Bahia. O objetivo principal era apoiar nove comunidades rurais $(250$ famílias) na elaboração de um projeto global de desenvolvimento local, com base nas suas demandas (Caron et al., 1993). A "Nova Metodologia", como ficou conhecida a experiência, baseava-se em um diagnóstico participativo, estudo de realidade, discussão com os agricultores e suas famílias e restituição dos resultados em reuniões comunitárias. Pode-se dizer que foi uma das experiências pioneiras de desenvolvimento local no Brasil (Barros et al., 1999b).

No marco da construção e execução do Projeto Global de Desenvolvimento de Massaroca, as primeiras preocupações se deram em torno da produção agropecuária e da organização dos produtores com o objetivo de assegurar e prosseguir o esforço de geração, adaptação e difusão das inovações tecnológicas às necessidades de gerenciamento dos recursos locais. Com a evolução dessas questões, percebeu-se que a educação era elemento preponderante para o entendimento e assimilação do novo modo de pensar, agir e viver no local (Barros et al., 1999a).

Neste sentido, os atores do processo do desenvolvimento de Massaroca já vislumbravam uma ruptura da via do desenvolvimento vigente entrando em sintonia com a abordagem atual, como ressalta Martins (2006, p. 6), ao dizer que

[...] tanto a Educação quanto o Desenvolvimento vêm de uma tradição - a Tradição Moderna - em que os princípios mais caros foram a racionalidade, a universalidade, a imparcialidade, e a neutralidade. Tanto o desenvolvimento quanto a educação deveriam estar pautados por estes princípios universais. E mais, sem contar que mesmo que a educação tenha sido promovida a "alavanca” do desenvolvimento, o próprio sistema que pronunciou isso não se responsabilizou em torná-la acessível a todos. Além disso, tanto o desenvolvimento quanto a educação precisavam ser descontextualizados. Os grupos humanos, as comunidades, as culturas, os saberes, as tecnologias, vida em si destes grupos humanos, eram tomados como coisas que deveriam ser apagadas ou silenciadas, porque eram tidos como empecilhos ao desenvolvimento.

Isso porque o mesmo desenvolvimento e a mesma educação que se diziam universais e neutros, de fato, emanavam de interesses nada neutros, como conclui Martins (2006) em sua fala. A ruptura dessa via de desenvolvimento se deu exatamente quando surgiu a necessidade de introduzir os temas culturais e educativos como novos eixos do "projeto", firmando-se como prioridades para aumentar as capacidades humanas locais. 
Este texto tem a finalidade de apresentar e compartilhar um pouco esta experiência, particularmente a prática pedagógica da Escola Rural de Massaroca. Trata-se do relato de uma experiência pertinente ao momento atual, quando está se discutindo a reorientação de uma educação contextualizada.

\section{A escassez de fundamentação teórica no campo da "eduçação do campo"}

Pesquisar a relação escola e desenvolvimento local não tem sido algo simples como aparentemente pode parecer. Quando tornamos o olhar para a escola rural nos damos conta que poucos foram e são os suportes teóricos referentes à Educação do Campo. Este campo da educação foi por muito tempo abandonado não só nos aspectos didático-pedagógicos, como também na produção de conhecimento. Revirando um pouco a história da educação brasileira, em relação à produção científica sobre as escolas rurais, vamos encontrar alguma coisa somente depois de meados da década de 1960, voltando a aparecer novamente na agenda de poucos pesquisadores após 1998, com a realização da I Conferência Nacional de Educação do Campo. Embora havendo um interesse maior por parte de alguns educadores a partir desta data, muitos desses estudos voltaram-se mais para as escolas famílias agrícolas e as experiências das escolas do MST, que têm características bem particulares e diferenciadas da quase totalidade das escolas brasileiras espalhadas pelo Brasil e localizadas no campo.

Se na atualidade ainda são poucas as referências existentes e as abordagens que poderiam dar suporte teórico a esta discussão, imaginemos no início da década de 90, quando basicamente foi anunciado o desaparecimento do rural por alguns pesquisadores e pela academia, que propagavam que o rural sucumbiria ao processo "avançado" de urbanização. Nesse sentido, este relato da experiência da Escola Rural de Massaroca pode traduzir-se como um "vazio" teórico para alguns leitores, mas seu sentido é tornar-se "pleno" de fartos debates em torno do lugar e do contexto da Educação do Campo. Entendemos que é exatamente a partir da tematização/ sistematização das práticas e experiências educativas existentes nas escolas do campo que construiremos a teoria educacional com materiais autóctones que possam dar bases para os fundamentos da matriz pedagógica da Educação do Campo no Brasil.

No caso da Escola Rural de Massaroca (Erum), ela surge, inclusive, muito antes da aprovação da Lei de Diretrizes e Bases da Educação Nacional (Lei no 9.394/96) e da elaboração dos Parâmetros Curriculares Nacionais (PCNs). Seu principal referencial teórico foram os trabalhos e as contribuições do pedagogo brasileiro Luis de Sena, contemporâneo de Paulo Freire, com uma vasta experiência educacional em países da África, Ásia e Europa na área de formação e educação para o desenvolvimento local. Com ele idealizamos e construímos a Erum.

Não é do nada que partimos para desenvolver esta temática, pois tivemos a oportunidade de participar ativamente desse processo juntamente com o Comitê das Associações Agropecuárias de Massaroca (Caam) e a Associação de Desenvolvimento e Ação Comunitária (Adac), entre outras instituições, com o objetivo de, junto às comunidades rurais de Massaroca, elaborar uma proposta pedagógica para a implantação de uma escola de ensino fundamental de $5^{\mathrm{a}}$ a $8^{\mathrm{a}}$ série, que levasse em conta todo o contexto e a realidade desse contexto.

Durante mais ou menos oito meses, entre 1994 a 1995, juntamente com outros estagiários e técnicos ligados às mais diversas instituições participantes do projeto de desenvolvimento local de Massaroca, imergimos na realidade de suas comunidades rurais para apreender o sentido da vida cotidiana de seus habitantes, saber o que pensavam da escola, que escola queriam para os seus filhos, como funcionava a economia local, a produção, a organização social, a distribuição populacional (homens, mulheres, jovens, crianças, etc.) e quais eram suas principais necessidades e demandas.

De posse dessas informações, analisadas, restituídas e complementadas pelos agricultores e agricultoras, produtores e produtoras rurais, começamos a elaborar a proposta de educação rural, considerando a participação como o instrumento didático mais precioso nessa fase do processo de construção da proposta pedagógica.

Neste sentido, a proposta pedagógica não foi fruto apenas do conhecimento 
técnico, mas da real necessidade do contexto e dos atores e atrizes sociais locais, que não queriam ver mais repetidos os ciclos de analfabetismo e da ameaça de miséria que quase sempre se repetia naquela região semi-árida nordestina.

A cada produção escrita que se sistematizava buscávamos diversos referenciais que pudessem melhor embasar o trabalho, já que algumas experiências isoladas do Nordeste e de outras regiões do Brasil davam conta de um ensino contextualizado e que atendia às necessidades do povo do campo, como era o caso do Projeto Caatinga, em Ouricuri, PE, que visitamos na época.

Concluída a elaboração da proposta pedagógica, chegou o momento de retornar às comunidades rurais as informações sistematizadas e decodificadas, para que estas compreendessem de fato como seria colocado em prática tudo o que abordaram durante o período da imersão. Isso foi feito mediante o uso de diversas dinâmicas, de forma lúdica (reuniões, teatros, programas de rádio em linguagem popular, etc.), alimentando, assim, os sonhos de uma escola desejada pela população.

$\mathrm{Na}$ fase da apresentação da proposta ainda era possível aos atores locais se posicionarem, sugerindo ou alterando aquilo com que não concordavam, ou melhor, que não se adequava à sua realidade. Somente depois da passagem pelas diversas comunidades das quais se originariam os futuros alunos e alunas é que de fato foi formatada a proposta final. $\mathrm{O}$ processo foi demorado, cansativo, mas compensador, pois o resultado foi a validação do que foi idealizado antes e a definição de uma proposta de educação rural para o ensino fundamental de $5^{\mathrm{a}}$ a $8^{\mathrm{a}}$ série com pé na realidade rural. Isso foi possível porque já existia toda uma mobilização comunitária em torno do projeto de desenvolvimento local.

Vale lembrar que, em virtude da escassa produção escrita nesse campo, toda a construção coletiva (imersão nas comunidades, seminários, elaboração de resenhas de obras diversas, grupos de estudo, escrita e discussão da proposta) funcionou como formação pedagógica e embasamento teórico necessário para a atuação dos professores da futura escola, que previa, no seu itinerário pedagógico, elementos de estudo da realidade como instrumentos pedagógicos fundamentais no trabalho com os alunos no dia-a-dia da escola.
A produção da proposta, assim como a construção das primeiras salas de aula e do prédio escolar como um todo, deu-se de forma participativa; agricultores e agricultoras ajudaram desde a limpeza do espaço até a confecção dos blocos e levantamento das paredes, algo que demonstrava a riqueza da experiência. Essa dinâmica contribuiu para a definição dos princípios pedagógicos e valores que norteiam a proposta (solidariedade, ajuda mútua, cooperação, respeito às diferenças, valorização da realidade e da cultura local, etc.). A escola, afinal, foi inaugurada em maio de 1995, com uma turma inicial de $5^{\mathrm{a}}$ série e com uma proposta idealizada e construída coletivamente com os atores sociais locais.

É a partir desse tempo pedagógico vivenciado pela escola que buscamos, neste artigo, não trazer referenciais atuais, desconectados do trabalho ali desenvolvido, mas compreender a práxis educativa que aconteceu/acontece naquele espaço, o movimento de uma prática educativa que se coloca a serviço da construção do desenvolvimento local. Desde o começo, o povo de Massaroca sabia que a escola sozinha não seria capaz de dar conta dessa missão, mas que, juntamente com todos os órgãos que atuavam por lá, poderia contribuir para a escrita de uma nova história da educação do campo naquela realidade concreta.

\section{Refletindo sobre as práticas da escola rural de Massaroca (Erum)}

Antes de iniciar a descrição das práticas pedagógicas que vêm sendo gestadas na Erum, faz-se necessário dizer que a realização de uma experiência que leva em conta a tomada de decisão dos atores envolvidos na dinâmica do trabalho não é fácil, principalmente quando os saberes, os conhecimentos, as posições e os lugares de cada segmento que participa do processo de construção são diferentes. As dificuldades, no entanto, não foram sinônimo de bloqueios ou impedimentos para chegar ao fim, ou melhor, atingir os objetivos. As barreiras foram ultrapassadas. Assim foi o caso da legalização da escola junto ao Conselho Municipal de Educação e à Secretaria Municipal de Educação. Para que fosse legalizada, exigia-se uma 
entidade mantenedora, nas entrelinhas, o poder público local, neste caso a Prefeitura Municipal, que, a depender de quem ocupa o posto, reage aos princípios democráticos e participativos da população, principalmente quando se refere à população rural nordestina, historicamente dominada e manipulada.

Por se tratar de uma construção baseada no "saber-fazer" dos atores, principalmente dos atores locais, a primeira marca a ser ressaltada é a de que o processo foi dinâmico. Em sendo dinâmico, exigiu uma paciência pedagógica para acompanhar ritmos e processos diferentes, avanços e recuos. A Erum, hoje, não é a mesma de dez anos atrás - mudanças ocorreram. Quais são essas mudanças? Esta e outras questões ficam a merecer novas pesquisas, novos olhares, e, agora, com novos referenciais teóricos.

\section{Estrutura curricular - a inovação pedagógica}

O ano de 1995 é o marco inicial da experiência pedagógica da Erum. Sua estruturação curricular foi montada em blocos temáticos, comentados a seguir.

\subsection{Blocos temáticos}

Partindo das reflexões feitas ao longo da elaboração da proposta pedagógica da Escola Rural de Massaroca, foi montada uma estrutura curricular cujos conteúdos seriam trabalhados através de blocos temáticos, de maneira interdisciplinar.

Foram escolhidos quatro blocos temáticos que permitiam expressar os aspectos socioeconômicos e culturais da área de abrangência do projeto, de forma que a vida das comunidades pudesse estar dentro da escola. Assim sendo, o ensino se daria a partir do meio físico, social, cultural e econômico. Os blocos temáticos da proposta foram estruturados com base no saber popular das comunidades e nos conhecimentos globais articulados pela equipe técnica do projeto, sendo estes:

Agropecuária: englobava as atividades produtivas que asseguram a alimentação e a renda familiar, através da criação de caprinos, ovinos, bovinos e de pequenos animais, dos cultivos agrícolas (feijão, mandioca, melancia, etc.) e o manejo dos recursos naturais;

Cultura e civilização: dizia respeito à organização social, às relações de trabalho, às expressões culturais, aos costumes, à história e à vida social e política das comunidades envolvidas;

Atividades de transformação e serviços: reunia os temas relacionados com a infra-estrutura local, os bens e serviços, as atividades extra-agrícolas, as tecnologias e os equipamentos e utensílios usados no atendimento de outras necessidades das comunidades;

Saúde e nutrição: relacionava-se com o problema das doenças, a higiene, a alimentação e a água.

Cada bloco temático constituía um agrupamento de temas que, no seu bojo, faziam parte do cotidiano do aluno e eram desenvolvidos em sintonia com o ciclo da natureza, ou seja, de acordo com a importância que estes temas assumiam no espaço-temporal da vida da comunidade. Dentro desses blocos temáticos, alguns temas significativos foram evidenciados a partir da vivência da equipe do projeto na imersão do cotidiano das comunidades rurais durante o processo de idealização da proposta, como, por exemplo:

Agropecuária: a mandioca, a melancia, a cabra, a forragem, o umbuzeiro;

Cultura e civilização: a roda de São Gonçalo, a corrida de argolinha, a feira de Massaroca, a comunidade, a migração, a seca, a vaquejada;

Atividades de transformação e serviço: o queijo, a construção de cisternas, as estradas, o transporte, o couro, a farinhada.

Saúde e nutrição: furunculose, verminose, a água;

Nesse sentido, os temas passavam a ser "objetos de estudo", e dentro do esforço de compreensão e análise destes "objetos" é que reapareciam os conteúdos programáticos das disciplinas previstas no currículo escolar comum.

As disciplinas do núcleo comum e da parte diversificada eram contempladas, sendo que cada tema requeria naturalmente 
um conteúdo de uma determinada disciplina (disciplina introdutória), e as outras iam pouco a pouco dosadas. Cada tema determinava uma seqüência ou unidade de ensino que por si só condicionava o seu tempo de duração. O programa determinava uma coerência lógica (coerência interna), e a escola funcionava respeitando o aprendizado do aluno (coerência externa).

\subsubsection{Como trabalhar um bloco temático}

Bloco temático: agropecuária;

Tema: mandioca.

A mandioca é estudada como atividade humana; assim ela é vista como produto dentro de três ciclos produtivos: o primeiro agrícola, o segundo de transformação (industrial) e o terceiro de serviço (comercial).

Os ciclos da atividade se passam:

1) dentro de um meio físico que:

- se oferece como recurso;

- se apresenta como forças resistentes que o homem deve dominar utilizando sua força e sua inteligência;

- enfim, se manifesta como quadro limitante, que se impõe ao modo de trabalho do homem e à sua organização (ciclos naturais do clima, da planta, etc.).

2) dentro de um meio social onde:

- a mandioca é uma fonte da base de alimentação;

- ela representa um elemento importante para a conservação e a reprodução do grupo social;

- as atividades unem pessoas através de laços familiares, de trabalho, de clientela e administrativos.

\subsection{Itinerário pedagógico - o caminho metodologico}

Os conteúdos de cada tema são subdivididos em unidades, sendo que em cada unidade o tema é tratado adotando
Os conteúdos das disciplinas escolares mediante o estudo da mandioca

I. O que se pode estudar das disciplinas escolares da ciência dentro do tema mandioca.

a) O mundo em que vivemos (a água, o ar, o solo, o meio ambiente como um todo).

b) Os seres vivos (evolução da planta, seus órgãos e suas funções, sua classificação, analogia com outros vegetais).

c) O homem (função digestiva e nutrição; elementos tóxicos nos alimentos).

d) A matéria e a energia (alguns fenômenos físicos e químicos).

II. As disciplinas escolares de natureza social a) Geografia (orientação e localização; clima e estações: movimentos da terra; atmosfera; relevo; população; cidade e campo; a formação de cidades; os sistemas de transporte; atividade econômica: a agricultura, transformação e o comércio).

b) História (história contemporânea do Vale do São Francisco: os pólos de desenvolvimento, a irrigação e agricultura tradicional; história da colonização e ocupação do Vale e os tipos de agricultura; o valor do trabalho; a remuneração justa; a proteção social; as responsabilidades do Estado; as organizações de produtores; festas e costumes locais em torno da vida rural; o folclore).

c) Religião (o homem em sociedade; o valor religioso do trabalho; o trabalho agrícola no Antigo Testamento; o trabalho no Novo Testamento; as festas religiosas).

III. As disciplinas escolares que dizem respeito à expressão e às atividades

a) Português (produção de textos sobre o conjunto de temas; leitura e compreensão de textos de diferentes gêneros literários sobre os temas tratados anteriormente; aspectos gramaticais; exercícios de oralidade).

b) Matemática (aplicação do programa aos conteúdos e às práticas pedagógicas identificadas anteriormente; teoria dos conjuntos e dos números; frações, razões e proporções; pesos e medidas; figuras planas; iniciação ao cálculo de vetores)

c) Educação Artística (figuras geométricas; audiovisuais para a restituição de trabalhos de observação no campo e divulgar os textos e documentos produzidos).

d) Diversificada (inúmeras aplicações práticas). 
um itinerário pedagógico composto por três momentos lógicos:

- Primeiro momento: a observação (estudo de meio);

- Segundo momento: a busca da compreensão (estudo científico);

- Terceiro momento: a volta ao real (trabalho prático).

O guia diário do educador é a ficha pedagógica, que segue o itinerário pedagógico previamente elaborado. Para cada unidade são elaboradas as fichas pedagógicas referentes à abordagem do tema em estudo, bem como uma ficha para acompanhamento individual do aluno. $\mathrm{O}$ conjunto das fichas pedagógicas é incorporado a um banco de dados, que registra todo o trabalho desenvolvido durante o ano letivo. Esses três momentos podem ocupar todo o dia letivo, com, em média, duas horas para cada um, e são avaliados com a mesma significação. Também, podem ser trabalhados durante uma unidade ou no desenvolvimento integral de um tema, ocupando assim uma carga horária variável dos três momentos.

a) Estudo de meio - O estudo de meio corresponde ao contato com o assunto dentro do tema a ser estudado mediante o exame ou levantamento de dados sobre o objeto e o fenômeno, permitindo assim dar início ao processo de abstração e conceitualização. Nesse estudo, o saber popular é revitalizado e introduzido no ensino. A visão é interdisciplinar, e o trabalho fica sendo percebido na intersecção das relações homem-sociedade e homemnatureza, através da comunicação entre os saberes diversos. Para Sena (1994), a preocupação é de fazer ver a realidade como um todo coerente, cheio de implicações mútuas e interdependências. Isso implica compreender cada elemento para, em seguida, reconstituir o real como um todo em que se manifesta.

As formas e os instrumentos deste estudo são variados e dependentes do conteúdo, do objetivo e do local onde são efetuados. Podem ser utilizados o estudo de paisagem, o mapa mental, a reunião, visitas às comunidades, roças, riachos, fundo de pasto, outros locais e outras comunidades. Os alunos, sob orientação de um ou mais educador, observam, entrevistam, conversam, recolhem dados e materiais. Na sala de aula, podese também observar objetos e fenômenos, entrevistar pessoas das comunidades que podem falar sobre determinado assunto e/ou demonstrar práticas utilizadas no cotidiano, etc.

Os dados e informações coletados nesta etapa são identificados, classificados, sistematizados e restituídos ao final de cada estudo. Esta etapa também permite a formação de um "banco de dados", podendo ser estruturado na biblioteca escolar.

b) O estudo científico - É o momento específico do ensino formal, onde se adquire as informações necessárias para compreender a realidade do objeto e fenômeno estudados. Esta é a hora de trazer a contribuição das ciências, pois melhor do que explicar é ensinar a procurar a explicação. Segundo Sena (1995), isso deve se constituir um hábito de discussão com o grupo, buscando soluções, fazendo pesquisas nos livros, etc.

c) Trabalho prático - Sempre que possível, deve-se, nesta etapa, voltar para verificar como se dá a "complexidade da realidade”. A reprodução do fenômeno é um bom instrumento de aprendizagem científica. É nesse exercício que se faz a conexão entre teoria-prática, escola-trabalho e escola-comunidade, por meio:

i) da experimentação de técnicas que preparem os alunos para transformar a realidade com base nos conhecimentos adquiridos nos dois primeiros momentos;

ii) da realização de um trabalho que ofereça um produto acabado, em nível da própria família, em benefício da comunidade e/ou da própria escola, ou mesmo de atitude comunitária.

Os objetivos que se pretende alcançar com este momento pedagógico são:

a) pôr em prática o estudo teórico;

b) educar para e pelo trabalho;

c) produzir coisas úteis para a escola e a comunidade;

d) ensinar a comunidade com exemplos concretos.

Por certo, este momento sofre limitações referentes a sua ligação com o 
estudo científico, pois este possui um ritmo próprio em função do calendário escolar. Associando-se a isto vem o fato de que se dá maior valorização ao conhecimento do que a sua aplicação e a incerteza das proposições que realmente provocam uma ação transformadora.

Esse foi o desenho inicial da proposta pedagógica que se buscou exercitar na Erum, considerada na região, no seu tempo e lugar, como uma experimentação educacional válida que deve ser apropriada.

\subsection{Reestruturação dos blocos temáticos - um atendimento à práxis pedagógica}

No processo de implementação da proposta, muitas adaptações e adequações foram feitas. Atualmente, a proposta está estruturada em cinco blocos temáticos, a saber:

Bloco Espaço - Tem como objetivo estudar as origens e evoluções dos espaços do mundo rural, do mundo urbano e do planeta, a partir das problemáticas e potencialidades do espaço rural onde a escola está inserida. Este bloco tem à frente a disciplina de Geografia, mas integra as contribuições das diversas áreas do conhecimento - Português, Matemática, Educação Artística - através das práticas interdisciplinares e transversais.

Bloco Organização Social - Para produzir e melhor utilizar o espaço em que vive, é necessário que o homem e a mulher estejam organizados. Neste bloco a escola busca desvendar o processo de organização social do homem e da mulher rural, como caminho para buscar a solução dos seus problemas, desenvolvimento do espírito de ajuda mútua e da construção da solidariedade. Este bloco é puxado pela disciplina História, que, a partir da organização familiar (célula básica da sociedade), estuda as demais organizações sociais do País e do mundo, também de forma interdisciplinar e transversalmente, com a participação de alunos, demais professores e comunidade local.

Bloco Processo Produtivo - No mundo rural o homem e a mulher são os principais agentes da transformação do espaço, buscando produzir algo para suprir suas necessidades. Neste bloco, a escola estuda vários processos produzidos no mundo rural nordestino e semi-árido. Vai desde as técnicas mais rudimentares utilizadas pelos/as sertanejos/as que moram no campo para produzir, até os caminhos que seguem a sua produção e o seu destino final: atravessadores, mercado, indústrias, supermercados, mercearias, consumidor final, etc. Procura-se o caminho que permita melhor produzir e a valorização dos produtos locais. Esse bloco é coordenado pela disciplina "Técnicas".

Bloco Necessidades de Vida-Sabemos que o espaço rural existe também pela ação do homem e da mulher e que ambos enfrentam várias dificuldades e passam por sérias necessidades que não podem ser ignoradas pela escola. Neste bloco a disciplina Ciências busca trazer esses enfoques para dentro da sala de aula, como também puxa a escola para as comunidades. Além de estudar e propor possíveis soluções para os problemas e necessidades enfrentados pelos/as homens/mulheres do semi-árido, a Erum procura trabalhar de forma interdisciplinar e interinstitucional com a participação de alunos, professores, comunidades e entidades governamentais e nãogovernamentais que atuam no campo, ou seja, atores internos e externos.

Bloco Convívio Social - Este bloco tem como objetivo fortalecer cada vez mais a relação escola-comunidade. O tema a ser trabalhado reflete os conteúdos desenvolvidos em cada unidade, todos os responsáveis pelas disciplinas trabalham conjuntamente e todas as séries se mesclam em atividades preestabelecidas. As comunidades também participam desde a fase do planejamento até a execução das atividades do dia. É um momento muito importante, em que a restituição dos conhecimentos adquiridos pelos alunos é realizada, provocando a sua socialização e reflexão e repercutindo, dessa forma, nas ações do Plano de desenvolvimento das comunidades.

Este bloco é responsável pela animação cultural, reforçando assim o convívio dos diferentes atores sociais que habitam o espaço, têm necessidades comuns e se organizam socialmente para melhor desenvolver o seu processo produtivo, sem que percam a ajuda mútua e a solidariedade, para conviverem socialmente. A formação desse bloco se deu a partir de 1998 (quarto ano de existência da escola) e acontece uma 
vez em cada unidade escolar ou mesmo ao final de cada estudo de realidade.

Dessa forma, tem-se tentado, mediante os estudos de realidade, levantar os principais problemas, potencialidades, aspectos culturais, econômicos, sociais e políticos das comunidades rurais que compõem a escola. Procura-se estudar, discutir e redefinir alguns destes aspectos, através de uma ação interagida entre alunos, professores e comunidades para o fortalecimento da ação coletiva, visando consolidar uma via de desenvolvimento sustentável com base nas capacidades locais. Objetiva-se com isto fazer que o camponês nordestino se veja como um "cidadão”, pois quando este objetivo for atingido outros aspectos mudarão, como a sua visão e a revalorização da sua auto-estima como pessoa, portanto, sua autonomia, libertando-se da dependência cristalizada.

Vale salientar que um trabalho deste porte não pode nem deve ser desenvolvido aleatoriamente, sem compromisso, vontade e postura política e ousadia para poder arriscar. Para isso, o planejamento semanal exerce uma função essencial, sendo esse momento utilizado para a realização de avaliação da semana anterior e, com base nesta, programar a atuação da próxima semana. Nos finais de semana, os alunos estão nas suas comunidades, ajudando os pais e, em alguns momentos, realizando atividades de pesquisas diversas originadas na escola.

\section{ESCOLA}

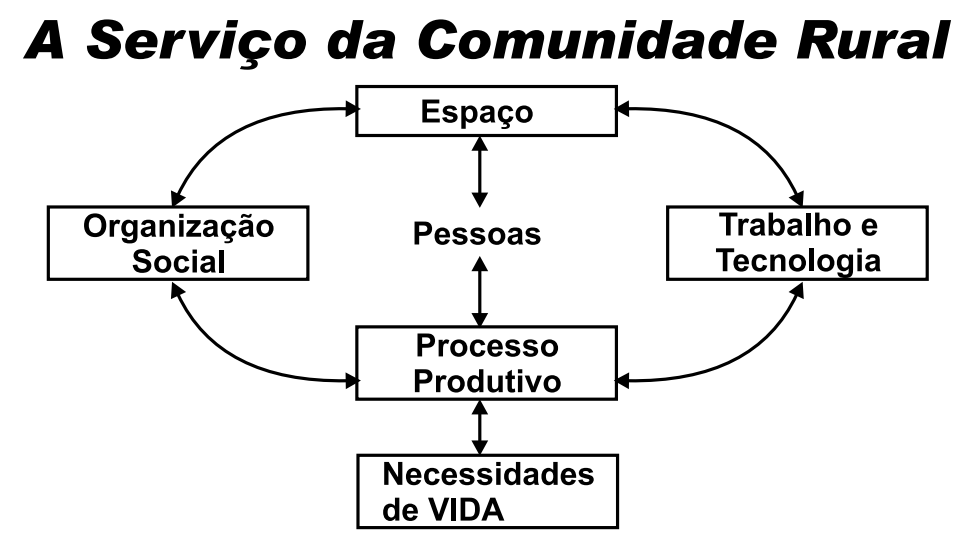

Figura 3: Fluxograma dos blocos temáticos

Fonte: Professores da Erum.

\section{Formação dos/as professores/as}

A formação dos/as professores/as dentro da implementação de uma proposta pedagógica como esta também assume uma posição de destaque. É preciso lembrar que as instituições são constituídas pelas pessoas que as habitam, e isso tem sido um dos principais pontos de estrangulamento do projeto em andamento. No início, a seleção dos professores foi realizada pela Universidade do Estado da Bahia (Uneb), Departamento de Ciências Humanas - Campus III, através de critérios preestabelecidos que configuravam o perfil imaginário, ideal para o professor da escola. Após quatro ou seis meses de experiência vivenciados em meio aos estudos teóricos e às comunidades rurais envolvidas na escola, esses professores seriam encaminhados à Secretaria Municipal de Educação para a devida contratação.

A formação constitui-se de três momentos, a saber:

$1^{o}$ Momento (saber) - Formação político-pedagógica, com destaque para os estudos de realidade;

$2^{\circ}$ Momento (ida à realidade - saber fazer) - Estudos de sistemas sociais, econômicos, culturais e políticos nas comunidades rurais, com destaque para a abordagem sistêmica das comunidades;

$3^{o}$ Momento (restituição) Devolução dos resultados dos estudos, com destaque para a análise dos problemas e potencialidades das comunidades abordadas. 
Com o concurso público de maio de 1998, a Erum recebeu o mesmo tratamento das demais escolas da rede municipal, e os novos professores concursados que assumiram imediatamente a função ficaram impossibilitados de passar pelo processo de formação. Tal fato provocou quebras momentâneas na condução da experimentação pedagógica, o que vem sendo corrigido com a própria formação em processo. Essa formação acontece dentro da vivência dos processos pedagógicos da escola. Também são propiciados aos/às professores/as momentos de formação e aperfeiçoamento mediante jornadas pedagógicas e seminários diversos promovidos pela Secretaria de Educação Municipal.

\section{A Escola Rural de Massaroca na perspectiva do desenvolvimento sustentável: uma prática à frente de seu tempo}

Desde sua fundação, em 1995, a Escola Rural de Massaroca já era uma escola à frente do seu tempo ou que conseguiu antecipar o futuro das políticas educacionais nas suas práticas educativas. $\mathrm{Na}$ sua proposta de reorientação curricular isso ficou evidente, pois antes da aprovação da Lei no 9.394/96 (Lei de Diretrizes e Bases da Educação Nacional), a Erum já estava fazendo na prática uma escola voltada para a realidade concreta do campo, o que somente vem ganhar espaço na legislação entre 1996 e 2002.

Uma das práticas que se destacam nessa experiência tem sido o estudo de realidade, que na Erum é realizado de diversas e variadas maneiras, sendo que, neste caso específico, destacamos o estudo do sistema fundo de pasto, ${ }^{2}$ desenvolvido pelos alunos da $8^{\text {a }}$ série, durante o ano de 2003.

O referido estudo visava compreender todo o sistema de fundo de pasto existente nas comunidades rurais de Massaroca, buscando assim levantar as suas problemáticas, potencialidades e implicações no sistema produtivo local a partir de uma análise crítica e potencial da sua capacidade de suporte diante da grande quantidade de animais que dele se utilizam, já que, para muitos, a caprino-ovinocultura é a única fonte de renda aliada à pequena agricultura de sequeiro e, em raros casos, à criação de bovinos.
Essa atividade foi escolhida para ser apresentada na Pré-Conferência de Educação para Convivência com o Semi-Árido Brasileiro, onde os alunos que participaram deram uma aula de compreensão do ecossistema local, destacando a importância do bioma caatinga. Fizeram relações diversas com a situação do ambiente local, a sobrecarga de animais para a quantidade de pasto e o que poderia acontecer no decorrer dos anos se não fosse tomada uma providência por parte dos criadores das comunidades rurais: Tragédia dos Comuns, de Garrett Hardin (metáfora do manejo de recursos de propriedade comum).

O trabalho demonstrou que existem algumas comunidades que possuem um rebanho imenso com um fundo de pasto pequeno, não suportando assim o abastecimento dos seus animais. As aguadas existentes são poucas e com baixos volumes de água, assim como a capacidade de pasto disponível. A escassez desses recursos faz com que os animais migrem para outras áreas, onde também já existem outros animais. Nesse caso, grandes problemas começam a acontecer, e isso tem provocado tanto a escola como os alunos a levarem esta problemática para a discussão nas reuniões do Comitê das Associações Agropecuárias de Massaroca (Caam). Isso tem possibilitado aos criadores de Massaroca um repensar da sobreexploração desse tão importante espaço de criação comunitária, assim como aos alunos retornarem para a vida concreta o objeto dos seus estudos como um inéditoviável instrumento de transformação das práticas cotidianas dos atores e atrizes que fazem essas comunidades.

O mais importante desse e dos demais trabalhos didáticos desenvolvidos na Erum é a demonstração de amadurecimento do papel que essa escola exerce na vida desse ambiente rural, onde as atividades pedagógicas conseguem extrapolar o simples sentido do conteúdo pelo conteúdo, prática bem comum nas escolas do nosso País, mas ir muito além, possibilitando aos alunos o desenvolvimento de uma compreensão mais ampla do mundo em que vivem, mas tendo como princípio fundante das suas ações a relação concreta com o ecossistema.

Vale lembrar que este mesmo estudo tem contribuído para o desenvolvimento de uma visão multidimensional da realidade concreta do semi-árido, onde a partir de uma atividade como essa os alunos possam despertar para compreender, por 
exemplo, o jogo pelo poder no mundo globalizado, onde muitas vezes as nações mais poderosas transformam as nações subdesenvolvidas em vítimas das suas ameaças e do seu poderio econômico, o que por analogia se faz na situação citada acima, onde as comunidades que possuem mais animais (sem critérios de qualidade) terminam por comprometer a vida e o desenvolvimento das que possuem menos, já que estes têm que dividir o mesmo espaço.

Retomando esta reflexão para o campo da educação com foco para o desenvolvimento sustentável e considerando que o desenvolvimento "não é um ideal nem uma catástrofe, mas antes de tudo um objeto de estudo" (Olivier de Sardan, 1995), e que o sustentável trata das co-responsabilidades para com critérios públicos de convívio coletivo e de cuidado com o meio e com o outro (Martins, 2006) é que as práticas pedagógicas desenvolvidas pelos/as professores/as e alunos/as da Erum, através do seu itinerário pedagógico, permitiram ir à comunidade e trabalhar os diversos conhecimentos. O que se buscava era explicar o processo complexo que aparenta como simples, que é a realidade (o meio ambiente, as condições de vida, as necessidades, o processo produtivo, as relações de poder, a organização social, os processos de convivência, etc.), para que, com ações e/ou atitudes concretas, a população possa transformar esta realidade.

A experiência mostrou que na Erum não há a necessidade de dizer se estamos discutindo agora educação ambiental ou desenvolvimento sustentável, pois a compreensão da primeira como prática transversal tem permeado todas as suas ações, onde o resultado maior é a construção de uma nova ética nos relacionamentos socioeconômico, político, institucional e ambiental. Olivier de Sardan (1995, p. 17) ressalta que as práticas e as representações das populações, em face da mudança em geral e do desenvolvimento em particular, mobilizam todos os registros possíveis, e ninguém pode ser, a priori, excluído ou desqualificado de avançar, nem o econômico com suas relações de produção e seus modos de ações econômicas, nem o político com suas relações de dominação e suas estratégias de poder, nem o social, o simbólico ou o religioso. A socioantropologia do desenvolvimento não pode se decompor em subdisciplinas: a transversalidade de seus objetos é indispensável à sua visão comparativa. Portanto, uma antropologia da mudança social e do desenvolvimento é por sua vez uma antropologia política, uma sociologia das organizações, uma antropologia econômica, uma sociologia das redes, uma antropologia das representações e sistemas de sentidos (Olivier de Sardan, 1995). Foi nesta perspectiva que a Escola Rural de Massaroca formou e forjou os seus pilares de educação do campo e no campo.

\section{Considerações finais}

Como bem reflete Luiz de Sena, "o serviço de educação só tem sentido se for realizado segundo os interesses da comunidade. Portanto, a realidade na qual está inserida continua a ser a grande inspiradora da proposta pedagógica. Ela deve ser vista como uma grade transversal e é por isso que a diversidade do meio deve ser considerada" (Sena, 1996).

Um dos grandes desafios nessa trajetória da Erum foi responder à confiança depositada pelos alunos e pelas comunidades em geral, que acreditaram ter a certeza de possuir uma escola transformadora, pensada e construída em conjunto com a comunidade, trabalhando para o seu crescimento e desenvolvimento sustentável. Por outro lado, a Erum é o elemento de maior impacto do Projeto de Desenvolvimento das Comunidades Rurais de Massaroca, pois a sua institucionalização é a concretização materializada da luta do Caam por melhores dias e condições de vida.

$\mathrm{O}$ caminho percorrido pelas comunidades é comprido. As pessoas mais ativas na organização dos agricultores e os jovens que por lá passam e passaram têm uma percepção do sistema em que vivem e, portanto, pouco a pouco, vão adquirindo as ferramentas essenciais para sua transformação na busca do desenvolvimento sustentável, onde os aspectos econômicos, sociais, culturais e ambientais pressupõem a mesma importância.

A educação assume, com certeza, um papel importantíssimo nesse caminho percorrido até o momento, uma vez que possibilita uma real leitura do meio pelos atores e atrizes que habitam esse espaço, permitindo, assim, o entendimento de que, na região semi-árida, a seca é um fenômeno natural que faz parte do cotidiano e que é necessário se buscar alternativas de convivência (as que já se tem e as que podem ser criadas), para que cada um tenha uma 
qualidade de vida melhor e possa usufruir dignamente da sua cidadania de forma coletiva, com eqüidade.

Entretanto, a educação não é um fim em si mesmo, pois, como diz Araújo apud Reis (2004, p. 61), a palavra educação, etimologicamente, origina-se do latim educere, que vai significar "conduzir, levar as pessoas para fora do lugar onde estão", lugar compreendido na perspectiva cultural, antropológica, social, política, econômica, etc., onde os sujeitos humanos tecem e entretecem sua história tingida de significados, sentidos e saberes. Nessa experiência ela é somente parte de um projeto de desenvolvimento das comunidades de Massaroca, e sua contribuição só será efetiva se estiver associada a outras políticas de apoio (ação fundiária, crédito, acesso ao mercado, infra-estrutura física e social, etc.) que possibilitem ações de continuidade.

Nesse sentido, o compromisso com a informação e com a educação e a troca de experiências entre as pessoas de todos os níveis e de todas as idades devem ser uma constante, o que possibilitará a reflexão e ação como prática de cada indivíduo, não como um esforço a favor de programas ou sistemas econômicos internacionais, mas a favor e em benefício de toda a coletividade.

O desenvolvimento "sustentável” não pode ser uma promessa, nem uma proposta que possa ser pensada e administrada apenas por alguns membros da comunidade, mas por todos, já que a lógica da sustentabilidade deve ser a de uma compreensão de sistema, em que todos devem estar comprometidos com os fins a que este servirá, que é a própria comunidade local, e, numa escala maior, a própria vida e garantia da existência da humanidade (Reis, 2004, p. 73).

Ainda são muitos os desafios. Alguns deles se apresentam em forma interrogativa. Como valorizar a experiência aprovada pelos alunos, pelos pais, professores e visitantes nacionais e internacionais, se mesmo o município ainda não a assumiu como um espaço de formação de formadores para replicar a experiência? Como uma experiência dessa natureza pode engrossar o rol de algumas outras para se transformarem em referências para diretrizes de políticas de educação do campo? Como não deixar tombar esta experiência pedagógica de uma escola contextualizada, que no momento passa por sérias dificuldades, comprometendo sua continuidade?
A especificidade do contexto em que se insere a Erum não permite maiores generalizações para outras realidades, mas pode servir de parâmetro para se buscar o pensar de novas experiências voltadas para a educação básica do campo, já que os seus elementos metodológicos e a sua intencionalidade podem ser considerados em qualquer realidade, dando conta de estudar o real, bem como dando a possibilidade de extrapolar para os outros níveis do conhecimento.

Nesse sentido, ressaltamos a eficácia, quando da utilização na prática. dos instrumentos pedagógicos, dos princípios da proposta pedagógica e da importância que é dada aos saberes locais como ponto de partida para a construção e aquisição de novos conhecimentos. Essa é a maior riqueza da Erum, o que coloca a experiência como um referencial. Ao se pensar abordagens desta envergadura, ainda prevalecem, no campo, a preponderância de escolas que de rural possuem apenas o nome, o que também tem sido, em muitos casos, respaldado pelos órgãos responsáveis pela Educação.

Mudar essa lógica e tentar furar este cerco parece ser um dos maiores desafios, pois o que percebemos até então, apesar das aberturas deixadas pelas mudanças recentes nas leis e nos parâmetros que norteiam a educação no Brasil, é uma letargia, por parte do poder público, no que se refere à redefinição da política educacional para o campo, que só recentemente começa a ganhar novos rumos.

Somos adeptos do pensamento de Edgar Morin (2006, p. 16), quando diz:

\footnotetext{
Educar para a era planetária significa que devemos nos questionar para saber se nosso sistema educacional está baseado na separação dos conhecimentos. Conhecimentos estes que as disciplinas separam, e não somente elas as separam como tampouco comunicam. Nós aprendemos a analisar, a separar, mas não aprendemos a relacionar, a fazer com que as coisas se comuniquem. Tudo está ligado, não só na realidade humana, como também na realidade planetária. Portanto, podemos imaginar que nosso sistema educacional é inadequado.
}

Assim sendo, precisamos desconstruir velhas e construir novas práticas, como a da Escola Rural de Massaroca e outras que sucessivamente se recriam em outros lugares e contextos. 


\section{Referências bibliográficas}

ARAÚJO, Miguel Almir Lima de. Educação e enraizamento: a fecundidade das raízes culturais na educação. Não publicado.

BARROS, Edonilce da R. et al. Desenvolvimento local e associações de pequenos agricultores: o caso de Massaroca (Juazeiro-BA). Petrolina, PE: Embrapa, 1999a. (Documentos da Embrapa Semi-Árido ; n. 127).

. Associações de agricultores familiares: uma alternativa de convivência no semiárido: o caso de Massaroca (Juazeiro-BA). In: SPERRY, S. (Coord.). Organização dos produtores e agricultura familiar. Brasília: Embrapa-CTT, 1999b. p. 43-61. (Série "Agricultura Familiar, 3").

BRASIL. Leis. Lei de Diretrizes e Bases da Educação Nacional, ${ }^{\circ}$ 9.394, de 20 de dezembro de 1996. Parâmetros Curriculares Nacionais: introdução aos parâmetros curriculares nacionais. Secretaria Educação Fundamental. Brasília: MEC/SEF, 1997.

CARON et al. Levar em conta as estratégias dos criadores na orientação de um projeto de desenvolvimento: o caso de uma pequena região do sertão brasileiro. Saragossa, Espanha, sept. 1993. p. 51-60. (EAP Publicação ; n. 63). Publicado no Simpósio Internacional sobre os Sistemas de Pecuária, Instituto Agronômico Mediterrâneo.

MARTINS, Josemar da Silva. A proposta de educação contextualizada e sua contribuição para o desenvolvimento humano e sustentável do Semi-Árido. Apresentado na I Conferência Nacional de Educação para a Convivência com o Semi-Árido Brasileiro. Juazeiro, BA, 17 a 20 de maio de 2006.

MORIN, Edgar. Conférence Edgar. Série Universo do Conhecimento. TV Cultura. Divulgada em junho de 2006.

OLIVIER DE SARDAN, Jean-Pierre. Anthropologie et développement. Essai en socioanthropologie du changement social. Paris: Karthala, 1995.

REIS, Edmerson dos Santos. Educação do campo e desenvolvimento rural sustentável: avaliação de uma prática educativa. Juazeiro, BA: Gráfica e Editora Franciscana, 2004.

ROLIM, A. N. Fundo de Pasto: um projeto de vida sertaneja. Salvador: CAR/INTERBA/ UFBA, 1987.

SENA, Luís de. Elementos para reflexão e avaliação do projeto de Formação Rural de Massaroca: Eixo escolar. Paris: IRFED,1996. 29 p.

. Formação de Professores para a Zona Rural. Paris: Irfed, 1995.

. Formação de Professores para a Zona Rural. Paris: Irfed,, 1994.

Edmerson dos Santos Reis, doutorando do Programa de Pós-Graduação em Educação da Faculdade de Educação da Universidade Federal da Bahia (UFBA), é professor assistente do DCH-II da Universidade do Estado da Bahia (Uneb).

Edonilce da Rocha Barros, doutoranda do Curso de Pós-Graduação Interdisciplinar em Ciências Humanas da Universidade Federal de Santa Catarina (UFSC), é professora assistente da Universidade do Estado da Bahia (Uneb).

Recebido em 15 de março de 2006.

Aprovado em 30 de agosto de 2006. 